\title{
The Use of Synchronous Videoconferencing Teaching to Increase Access to Specialist Nurse Education in Rural KwaZulu-Natal, South Africa
}

\author{
Jennifer Chipps* \\ Department of TeleHealth \\ University of KwaZulu-Natal \\ Umbilo Road, Umbilo, Durban, South Africa, 4000. \\ E-mail: chipps@ukzn.ac.za \\ *Corresponding author
}

\begin{abstract}
In KwaZulu-Natal more than 50\% of the population lives in the rural area but most of the health workers are based in urban centres where teaching hospitals and high incomes are common. Nursing provides the backbone of health care in the public sector. Specialist nurses such as advanced midwives or specialist HIV nurses are in short supply. Teaching via live synchronous videoconference (VC) provides an opportunity to extend specialist education to nurses at rural hospitals. Aim: The aim of the study was to review and evaluate the current use of videoconference education for nurses in KwaZulu-Natal. Methodology: A review the literature on VC education in nursing using bibliometric review strategies was conducted and two nurses' education courses conducted via videoconferencing was evaluated against a set of criteria developed and validated by the Department of TeleHealth at the University. Results: 81 publications addressing videoconference nurse education were found, most being published after 2000. Over half were descriptive studies, but were still valuable for informing this study. Based on the evaluation of the two courses against the set of criteria, the two courses were aligned sufficiently well with the measurement criteria. Additionally, the delivery of the courses via videoconferencing allowed for the identification of potential cost savings. Discussion: This evaluation indicates that these two courses have been successfully implemented using VC. In the light of the potential savings of time and money, VC can be used to teach specialist nursing courses to rural nurses. Recommendations to improve the VC courses included orientation training for presenters and encouraging more research regarding the effectiveness of VC as a teaching modality for clinical nurses in rural areas. Conclusion: More attention should be given to developing the infrastructure and skills to make this technology available and commonly used in health services in under-resourced public health services and hospitals. Additional research is also suggested.
\end{abstract}

Keywords: Videoconferencing (VC), Nurse Education, Rural, Tele-education.

Biographical notes: Jennifer Chipps is a lecturer at the University of KwaZulu-Natal, Durban, South Africa. She is the course coordinator of the Masters in Telemedicine programme and is completing her $\mathrm{PhD}$ in Telepsychiatry. She completed a Masters of Public Health from the University of NSW, Australia and worked as an epidemiologist in Australia and New Zealand prior to her return to South Africa. 


\section{Introduction}

South Africa has a quadruple burden of disease due to conditions related to poverty and under development such as maternal and peri-natal conditions, the emerging chronic diseases, injuries and Acquired Immune Deficiency Syndrome (AIDS) (Norman, Bradshaw et al. 2006). This is worsened by the fact that most of the health workers in the country are based in urban centres where teaching hospitals and high incomes are common (WHO 2006).

In KwaZulu-Natal (KZN), a province of South Africa with a population of approximately 10.3 million people, the need for quality health services is especially high. KZN has the fourth highest poverty prevalence (39.4\%) in the country (Bradshaw and Steyn 2002), over half (54\%) of the people live in rural areas (Health Systems Trust 2009) and it has the highest HIV/AIDS mortality rates (42\%) and child mortality rates in the country (Bradshaw, Nannan et al. 2000).

Nurses provides the backbone of primary health services in the public sector in South Africa but specialist nurses such advanced midwives are in short supply. In KZN, of the 21,131 professional nurses registered with the South African Nursing Council in 2006, only 57\% were working in public health services (Health Systems Trust 2009). There is also a high number of nursing vacancies throughout the country with an assessment by the WHO in 2003 finding more than 32,000 nurse vacancies (Padarath, Chamberlain et al. 2003).

Given the extent of the health service needs and the unavailability of skilled health professionals in rural and disadvantaged areas, the South African Department of Health's human resource plan and draft rural health strategy has been developed to increase the quantity and quality of professional nursing service in disadvantaged and remote areas. The provision of quality nurse training, especially for nurses in the rural areas, is therefore vital.

\section{Background}

Current professional nurse training is provided at universities and colleges of nursing and under the provisions of the Higher Education Act No. 101 of 1997. Nursing education in South Africa qualifies as "higher education" giving it the same status as education in other professions (Mekwa 2004). Traditionally, professional graduate specialist nurse training is centralized in urban areas.

The University of KwaZulu-Natal (UKZN), situated in the eThekwini district of the province of KwaZulu-Natal (KZN), South Africa, currently provides training for nurses through the School of Nursing (SON) and the Nelson R Mandela School of Medicine in the city of Durban. Registered nurses wishing to pursue a specialist career in nursing would have to migrate temporarily or permanently to the urban areas such as Durban in order to advance their education to progress in their clinical field.

The SON has been active in decentralized education for rural nurses since 1990, using a system of part-time decentralized tutors and clinical facilitators to run formal courses leading to registration with the South African Nursing Council. These courses could also be credited towards a Bachelor Degree in Nursing. Although this system has made education more accessible to rural nurses, it is limited by the time demands when specialists have to travel for hours to get to teaching sites, and by the lack of equipment in decentralized sites to demonstrate some of the advanced clinical techniques. 
Videoconferencing (VC) as a teaching modality has been widely accepted for delivering distance education courses to health-care professionals using audio, video and computers either synchronously or asynchronously (Curran 2006). VC specifically provides the opportunity for quality education opportunities for participants in rural and remote areas who due to time, travel, and cost constraints would normally be unable to access these (Birden and Page 2005). In Western Australia in the videoconference services set up for clinical telemedicine, educational use was about $40 \%$ of the time (Dillon, Loermans et al. 2005). Educational use normally include using videoconference for journal clubs (Ahn, Kim et al. 2007), ward rounds (Chang and Trelease 2001; Allen, Mann et al. 2007), continuing medical education (Allen, Sargeant et al. 2002; Curran, Keegan et al. 2007) and clinical assessment skills (Gul, Wan et al. 1999; Stain, Mitchell et al. 2005). Overall participants of these courses reported general satisfaction with the use of VC though some technical problems were reported.

The use of tele-education in nursing and medical courses are not new in South Africa with nursing courses being offered by satellite as early as 1990 (Pistorius and Du Pisani 1997). Over the last ten years, VC for telemedicine and the education of medical health personnel has been developed in KZN. The infrastructure, both at the university and at 30 of the 70 public hospitals, is spread across the province. At UKZN, a synchronous videoconference-based, medical postgraduate tele-education service was developed in 2001(Mars 2007). By 2006, 17 academic disciplines offered 765 hours of multipoint programming to 23,125 participants (Mars 2007). However, the use of VC teaching for nurses is not part of routine nurse education in South Africa and the SON has not previously provided nursing education using this modality. The available telemedicine and medical education videoconference infrastructure in the province provided an opportunity to enrich the university based nursing education to rural nurses.

Currently two specific nursing training courses are being offered using VC at UKZN. These are a two-day certificate course in HIV/AIDS and ARVs (ARV) and a specialist part-time two year Advanced Midwifery Course (ADM).

The first course is part of the Enhancing Care Initiative for HIV/AIDS training (ECI) at UKZN, a US President's Plan for Emergency AIDS Relief (PEPFAR) funded project. Jointly developed with the KZN Department of Health, and the Harvard University Division of AIDSA, this two day district-based clinical HIV/AIDS ARV certificate course is run once a year by ECI staff at the Medical School at UKZN. The aim of the course is to improve HIV/AIDS care and is open to nurses in primary health care clinics and hospitals in the rural areas. The course is offered using the existing telemedicine video-conference infrastructure at medical school and at three local district hospitals in the province. The course is technically supported by the Department of TeleHealth at Medical School and has been running since 2007.

The second course is a two year part-time Advanced Midwifery Course (ADM) offered by the SON for nurses residing in rural areas. The course is funded by Atlantic Philanthropies and with the assistance of the Department of TeleHealth; videoconference teaching was started in 2009 to five identified rural hospital sites. The course aims are: to improve access of rural women to Advanced Midwives at district level by increasing the number of these specialists in KZN; to improve the quality of midwifery services; and to build a mass of knowledgeable ADMs in KZN. The target is to train $120-160$ midwives over 3 years to become registered Advanced Midwives in the province.

The videoconference broadcasting is being conducted using Integrated Services Digital Network (ISDN) lines and interactive VC equipment which allow two or more sites to have live interaction via video and audio transmission. This set-up allows the 
presenter to use presentation slides. It also allows the presenter and students to visualize one another to discuss issues in a live interactive fashion. The digital compression of audio and video streams in real time is done via a codec which compresses and transmits a video stream through an ISDN network. Simultaneous videoconferencing from the Medical School site to the remote sites is done in a dedicated VC venue through a multipoint videoconference unit which includes:

- Video camera providing video input

- Television monitor and projectors providing video output:

- Microphones for audio input

- Loudspeakers for audio output

- A personal computer with PowerPoint and a scan converter for slide conversion

Each of the remote sites has a dedicated VC venue based in the local rural hospital which is equipped with a single point videoconference unit. Most venues have only 128kilobytes per second (kbps) stream range available resulting in the VC sessions being broadcast at $128 \mathrm{kbps}$.

\section{Aim of Study}

The overall aim of the study was to review and evaluate the current use of videoconference education for nurses in KwaZulu-Natal. This included: A review of the literature on the international use of $\mathrm{VC}$ for nursing education; and an evaluation of the two current courses for rural nurses at UKZN which are being conducted via videoconference, namely the two day, district-based clinical ARV course (ARV) offered by the Enhanced Care Initiative (ECI) and the Advanced Midwives (ADM) course offered by the SON.

\section{Research Methods}

To review the literature on $\mathrm{VC}$ education in nursing, standard bibliometric review strategies were used. The search terms: "nursing" and "education" and ("videoconference" OR "videoconferencing") were used to search the following databases: Academic Search Complete, Pubmed, CINAHL, Health Source, Google Scholar and ERIC.

The evaluations of the two nurse education courses were part of the routine evaluation of all VC education courses supported by the Department of TeleHealth in 2008 and 2009. The routine evaluations focus on the VC implementation process and participants' satisfaction with the technology against a set of evaluation criteria (using $75 \%$ as an indicator) developed by the Department of TeleHealth. The first tool is a standard routine audit $\log$ which records the number of participants from each VC site for each session. The second tool is a standard VC Evaluation questionnaire, developed by the Department of TeleHealth, which is routinely administered to participants of VC courses. The questionnaire includes questions on previous use, technical issues, general satisfaction with VC and perceptions of suitability of VC for education courses. The focus of the questionnaire is the quality of the videoconferencing and not the teaching content. The questions are 4 point Likert scales (Strongly Agree, Agree, Disagree, Strongly Disagree or Very Satisfied, Satisfied, Dissatisfied Very Dissatisfied). Content validity of the questionnaire and criteria were established through a review of the 
literature on VC evaluations (Ho, Hu et al. 2006; Holland, Soundappan et al. 2008; Newman, Martin et al. 2009) and in consultation with VC administrative staff. Face validity was established through the review of the questionnaire by a TeleHealth expert. Reliability was tested using Chronbach's alpha with adequate alphas reported for both courses (ADM 0.75, ARV 0.81). Additional assessment of reliability and validity for this tool is planned as part of further studies. Frequencies and percentages were calculated and where appropriate, the two groups were compared using Chi-square tests $(\mathrm{p}<0.05)$.

\section{Results}

\subsection{Review of published articles on videoconference education}

A total number of 81 published articles were found on nursing education and videoconferencing. Most of the articles were published in Nursing and or Education Journals with 13 being published in telehealth journals (Table 1).

Table 1. Summary of published articles on VC education in nursing

\begin{tabular}{|l|c|}
\hline Journal & No. \\
\hline Education & 23 \\
\hline Nursing & 20 \\
\hline Other health journal & 13 \\
\hline Informatics & 10 \\
\hline Telehealth & 13 \\
\hline Year & \\
\hline $1990-1999$ & 14 \\
\hline $2000-2004$ & 39 \\
\hline $2005-2009$ & 28 \\
\hline Country & \\
\hline USA and Canada & 38 \\
\hline EU & 15 \\
\hline Oceania & 13 \\
\hline South America & 4 \\
\hline Asia & 5 \\
\hline Africa & 2 \\
\hline Middle East & 1 \\
\hline Type of VC education & \\
\hline VC only & 56 \\
\hline VC and other methods combined & 23 \\
\hline Type of article & \\
\hline Description & 44 \\
\hline Evaluation, Effectiveness, Reliability & 27 \\
\hline Review & 2 \\
\hline Other & 9 \\
\hline
\end{tabular}


Of the 81 articles, seven were published studies in developing countries. Four studies were reported from Brazil (Bastos and Guimarães 2003; Godoy, Costa Mendes et al. 2004; Seixas, Mendes et al. 2004; Peres and Leite 2008) and two from South Africa (Pistorius and Du Pisani 1997; McInerney and Nkosi 2007). One study was a report on an undergraduate program at the University of Pretoria to undergraduate nursing students via satellite (Pistorius and Du Pisani 1997), the second a pilot study in KZ-N on using videoconferencing to teach Nursing Management (McInerney and Nkosi 2007).

Most of the articles were descriptions of VC teaching (44) with only 27 of the studies being focused upon VC evaluation. In evaluating VC for teaching, the studies focused on participant satisfaction, comparison of knowledge and skills between face to face $(\mathrm{F} 2 \mathrm{~F})$ or in person teaching and VC presentations and the occurrence of technical issues such as quality of pictures and audio. Nineteen of the 27 studies focused on the implementation of VC education and two studies compared VC with F2F (Loewen, Seshia et al. 2003; Kerns, McDonough et al. 2006). Four of these studies evaluated the impact of the program reporting knowledge improvement (Hampton 1994; Sawada, Sugiyama et al. 2000; Gobbi, Monger et al. 2004; Seibert, Guthrie et al. 2004) with one study showing that there was little difference between F2F and VC teaching in achievement scores or the gain in achievement scores (van Boxell, Anderson et al. 2003).

Five studies reported on the nurses' perception of benefits and preferences for $\mathrm{VC}$ (Cragg, Andrusyszyn et al. 1999; MacIntosh 2001; Cartwright and Menkens 2002; Charles and Mamary 2002). Overall, studies reported that the nurses found the experience rewarding and beneficial (Weber and Lawlor 1998; Tachakra and Creagh-Brown 2001; Jones, Skirton et al. 2006; Winters 2007; Zerr and Pulcher 2008; Newman, Martin et al. 2009). Two cost analysis of studies were found (Regnard 2000; Tachakra and CreaghBrown 2001).

In summary, the number of reported studies was low but an increase in related publications from 2000 onwards is noted. A small proportion of the publications identified were evaluations of videoconferencing education courses for nurses, focusing primarily on process evaluations of satisfaction and technical issues in implementation. Overall participants reported finding the experience satisfactory. Of the studies that did compare F2F and VC teaching, knowledge improvement was reported for $\mathrm{VC}$ teaching. There is a need for more research and evaluation in the area of $\mathrm{VC}$ teaching for nurses.

\subsection{Evaluation of two $\mathrm{VC}$ nursing education courses}

The questionnaires were administered to the participants at the end of the two-day ARV course in $2008(n=186)$, and at Month $1(n=47)$ and Month $6(n=53)$ in the ADM course in July/August 2009. A matched comparison study between the 1 and 6 month evaluation data of the ADM course is in press (Chipps and Mars 2009). This paper focuses only on the 6 month ADM evaluation and the ARV evaluation. The 6 month ADM evaluation was selected to evaluate well established courses against the evaluation criteria.

\section{Criteria 1. Successful implementation of VC courses}

The ARV course (two 8-hour sessions) was broadcast by the Department of TeleHealth to three sites from the central site in Durban in 2008. A total of 186 people participated in the course. One hundred and forty nine $(80.1 \%)$ of the participants were from remote non-Durban sites indicating that the course was reaching nurses in the rural areas. 
Teaching Advanced Midwifery via VC commenced in January 2009, with all the participants from rural sites. One three-hour session per week was broadcast from the Nelson R Mandela Medical School to four sites with about 47 nurses participating each week over the first six months. At the time of the evaluation, VC broadcasting was occurring to all five identified sites with a total of 53 participants attending. The delay at the fifth site initially was due to technical problems with the local equipment at the site.

For the ADM course, as expected with a new course, some hospitals were using the videoconference equipment for the first time and some technical issues were experienced. Nearly $68 \%$ of participants reported experiencing technical problems. In the ARV course, which runs regularly, only $23.2 \%$ of the participants reported experiencing technical issues ( $\chi 236.8 \mathrm{p}<0.0000$ ) (Table 2).

Table 2. VC Technical issues experienced

\begin{tabular}{|l|l|c|c|}
\hline Item & & ADM & ARV \\
\hline Good quality of picture of & Presenter & $38(75.5 \%)$ & $146(73.1 \%)$ \\
& Participants & $36(67.9 \%)$ & $107(58.5 \%)$ \\
\hline Good quality of sound from & Presenter & $40(73.1 \%)$ & $136(74.9 \%)$ \\
& Participants & $38(73.1 \%)$ & $135(74.6 \%)$ \\
\hline $\begin{array}{l}\text { Good quality of PowerPoint } \\
\text { presentations }\end{array}$ & & $29(55.8 \%)$ & $137(74.9)^{* *}$ \\
\hline No Technical Problems & & $17(32.1 \%)$ & $139(76.8 \%)^{* *}$ \\
\hline
\end{tabular}

** Statistical significance $(\mathrm{p}<0.000)$

$*$ Statistical significance $(\mathrm{p}<=0.05)$

The quality of the sound was reported to be consistent at all the sites with between $73.1 \%$ (ADM course) and $74.9 \%$ (ARV course) participants agreeing that the quality of the sound was good. However, while most participants agreed that the presenters were clearly visualized $(73.1 \%-75.5 \%)$, the visualization of other participants were rated lower $(58.5 \%-67.9 \%)$. This may due to the split screen to view all sites at the same time or may indicate that presenters did not regularly stop to check in with remote sites during the presentation period allowing participants to see each other. There appears to be some disagreement around the clarity of the PowerPoint presentations with only $55.8 \%$ of the ADM participants agreeing that they could see these clearly as compared to the $74.9 \%$ of the ARV group ( $\chi 27 \mathrm{p}=0.007$ ) (Table 2).

\section{Criteria 2. Participants are satisfied with video-conference (VC)}

Satisfaction was measured by asking participants whether they would recommend $\mathrm{VC}$ courses to a colleague and whether they would attend videoconference sessions in the future. All participants strongly supported both statements with over $85 \%$ in both groups agreeing with the statements (Table 3). Only a small number, 24 (13.4\% ARV) and 9 (17\% ADM) of the participants reported that they would rather travel to Durban than attend VC. 
Table 3. Satisfaction with $\mathrm{VC}$ sessions

\begin{tabular}{|l|c|c|}
\hline Item & ADM & ARV \\
\hline Recommendation of VC to a colleague & $46(86.8 \%)$ & $168(92.3 \%)$ \\
\hline Attendance of future VC sessions & $49(92.5 \%)$ & $175(96.2 \%)$ \\
\hline
\end{tabular}

\section{Criteria 3. Suitability of VC as a teaching tool}

Appropriateness of $\mathrm{VC}$ as a teaching tool was measured by the level of comfort of the presenter as perceived by the participants, whether participants thought VC was equivalent to $\mathrm{F} 2 \mathrm{~F}$ teaching, the ability of $\mathrm{VC}$ to allow for interaction and its suitability as an educating tool for teaching their course (Table 4). The participants perceived the presenters in the ARV course to be more comfortable than the presenters in the ADM course $(\chi 215 \mathrm{p}=0.0008)$. A greater proportion of ARV participants felt that VC was a suitable and appropriate education tool for teaching their course than the participants in the AMD course. In comparing VC with face to face $(\mathrm{F} 2 \mathrm{~F})$ teaching and the amount of interaction it allows, both groups of participants overall felt that $\mathrm{VC}$ was comparable to $\mathrm{F} 2 \mathrm{~F}$ teaching in terms of interaction but more ARV course participants felt that it allowed for less interaction than F2F teaching ( $\chi 23.6 \mathrm{p}=0.05)$ (Table 4).

Table 4. Suitability of VC as an educational tool

\begin{tabular}{|l|c|c|}
\hline Item & ADM & ARV \\
\hline Presenter comfortable & $42(85.7 \%)$ & $181(98.4 \%)^{* *}$ \\
\hline Similar to Face to Face (F2F) teaching & $36(69.2 \%)$ & $129(72.1 \%)$ \\
\hline Ability to allow for interaction & $41(82.9 \%)$ & $124(68.1 \%)^{*}$ \\
\hline Suitability as an educational tool & $41(78.8 \%)$ & $163(89.4 \%)^{*}$ \\
\hline Appropriateness as an educational tool & $37(71.2 \%)$ & $163(89.6 \%)^{* *}$ \\
\hline
\end{tabular}

** Statistical significance $(\mathrm{p}<0.000)$

$*$ Statistical significance $(\mathrm{p}<=0.05)$

\section{Criteria 4. VC reduces the potential cost of attending courses}

Between $80-100 \%$ participants were from remote sites, living an average distance of about 300 to $500 \mathrm{~km}$ return journey to and from Durban. The average travel distance was $522.4 \mathrm{~km}$ SD 245.9 and $318.8 \mathrm{~km}$ SD 214.6 return journey to and from Durban, for the ADM and the ARV course respectively.

$\mathrm{VC}$ has resulted in a potential reduction in potential travel for the participants and the presenters of the courses. Using the audit log files and the reimbursement rate of UKZN (R2.92 or $\$ 0.40$ per Km), the total cost of potential attendance of the training in Durban can be estimated for the ADM course (over a period of 6 months); and the annual ARV course (Table 5). Though students still had to travel to their own hospital to attend 
the VC sessions this is deemed to be similar to travelling to work and would therefore not be reimbursed by the employer. The saving in potential travel cost which would have been paid by the DOH for the two courses were therefore about R1.5M.

Table 4. Potential cost savings for travel for DOH based on current reimbursements for travel $(\mathbf{R} 2.92 / \mathbf{k m})$

\begin{tabular}{|l|l|l|l|l|l|l|}
\hline & $\begin{array}{l}\text { Average } \\
\text { KM to } \\
\text { and from } \\
\text { Durban }\end{array}$ & $\begin{array}{l}\text { Average } \\
\text { No. of } \\
\text { Remote } \\
\text { Students }\end{array}$ & $\begin{array}{l}\text { Potential } \\
\text { Times } \\
\text { Travelled }\end{array}$ & Total km & $\begin{array}{l}\text { Total } \\
\text { Potential } \\
\text { Cost (R's) }\end{array}$ & $\begin{array}{l}\text { Average } \\
\text { Potential } \\
\text { cost/participant }\end{array}$ \\
\hline ADM* & 522 & 47 & 18 & 441,612 & R1,289,507 & R27,436 \\
\hline ARV** & 319 & 149 & 2 & 95,062 & $\mathrm{R} 277,581$ & $\mathrm{R} 1,862$ \\
\hline
\end{tabular}

*6 months data

**excluding students in Durban

Connection costs (totals) were estimated to be about R16,842 for the ADM course over six months and about R3,743 for the 2-day ARV course based on standard call tariffs for 128kbps (2 lines @ R0.01083ps x sites x times connected x duration). Assuming that for the Department of Health to set up a videoconferencing unit is estimated at R200,000 (UKZN personal communication), the potential cost savings from the 6 months ADM course in of itself, could have paid for the set up of the 5 local videoconference venues $(1 \mathrm{M})$ and the running of these units for a year.

In terms of time spent travelling, additional potential cost savings can be estimated. The average travel time to and from Durban for the ADM participants was 8 hours and for the ARV course participants, 5 hours. When the time spent travelling to and from for each session and then for each of the total courses was calculated, VC teaching potentially could save at total of 6,768 hours of ADM nurses' travel time and 1,490 hours of ARV nurses' travel time. Since this is all on-duty time, and the average salary of a nurse is about R150,000 to R200,00 (KZN Department of Health 2009) per annum or about R100 to R130 per hour, the total additional cost for the employers of "time lost" would have been an estimated R676,800 to R879,800 for the ADM nurses and an estimated R149,000 to R194,000 for the ARV nurses.

In summary, when considered the criteria, implementation, satisfaction, suitability and potential cost savings, the benefits of $\mathrm{VC}$ for nursing education are markedly apparent. The technical issues experienced during the ADM course is one area the adherence to the target criteria could be strengthened. This was due to the difficulties in connecting to the fifth site and the initial set up problems when running a VC course for the first time. These types of technical issues when introducing a new innovation are not abnormal, and as long as rectified in a timely fashion, should not be considered in a negative light. 


\section{Discussions}

As in the review of the literature, the evaluations conducted in $\mathrm{KZN}$, focused primarily on the implementation process and a preliminary attempt to estimate potential cost savings. Overall high levels of satisfaction were reported by the with participants with them listing the advantages of attending VC as being able to share information with other participants and discuss issues with participants and experts from other sites. These findings are similar to what was reported by other studies with nurses finding the experience rewarding and beneficial (Weber and Lawlor 1998; Tachakra and CreaghBrown 2001; Jones, Skirton et al. 2006; Winters 2007; Zerr and Pulcher 2008; Newman, Martin et al. 2009) and to a previous VC pilot study in South Africa (McInerney and Nkosi 2007). In the McInerney \& Nkosi study of 125 Nurse Manager students, most enjoyed the opportunity to be able to communicate with students from other centres and expressed a desire to have more $\mathrm{VC}$ teaching.

In comparing VC with F2F course delivery modalities, the majority of the participants reported that they believed $\mathrm{VC}$ to be an appropriate and suitable educational tool. This finding is congruent with other international studies (van Boxell, Anderson et al. 2003). The ARV course participants had a significantly higher agreement with statements about the suitability of VC which may be due to the fact that this was a short course as compared to year long course for the ADM nurses and that the course had been run previously. Several international studies also support the value that students perceive in the use of VC for clinical courses similar to the ADM and ARV (Chang and Trelease 2001; de Godoy, Costa Mendes et al. 2004; Zerr and Pulcher 2008).

As has been borne out in international studies (Regnard 2000) and in these two courses, links were easy to establish and rarely failed regardless of distance, but some technical and communication problems were reported. The ADM course had some initial technical problems, related to the first time nature of this course being conducted via VC and the initial problems in connecting to the fifth site which were later rectified. Such initial problems tend to discourage people who have become accustomed to advanced information and communication technology (ICT). However, such problems are often temporary in nature and are common to innovative uses of ICT, therefore participants should be advised to expect initial problems and not feel demoralized or discouraged.

Transmission quality was also found to be satisfactory, with both audio and video quality meeting the required indicator, but also showing areas for quality improvement. Our findings are similar to those found in international studies where a majority of participants agreed that the audio (82\%) and video quality (91\%) affording by VC were acceptable (Armfield, Smith et al. 2007). Some of the issues reported in this study however, such as the noted difficulty with the PowerPoint slides, were not technical problems but related to presenter factors and presenter style. Apart from connection problems, most of the problems reported are related to user interaction with technology which can be addressed through enhanced training.

International studies suggested that success of the sessions often depended on the teacher's style (Post, Carusetta et al. 1998) or the group size (Tachakra and CreaghBrown 2001; Debourgh 2003). Though group sizes were large (>20) in both courses, both courses reported that the participants perceived the presenters to be comfortable using VC which may have contributed to the overall satisfaction with the courses. However, it is clear that the presenters in the ARV course which have been repeatedly offered were reported as seeming to be more comfortable with the technology than those teaching the ADM course which was offered for the first time. 
In this evaluation, the focus was on the implementation of the $\mathrm{VC}$ sessions and not whether knowledge transfer or learning occurred. Benefits were measured in terms of access and potential not actual cost savings. The courses increased access to participants (47 midwives in rural areas and to 149 primary health care nurses in rural clinics) who would either have had to travel to Durban or not have the training. In addition, though the estimations were based on averages and potential not actual savings, potential cost savings have been identified for the employers. Similar findings regarding improved access and increased cost efficiencies for VC coursework were also found in the literature (Regnard 2000; Tachakra and Creagh-Brown 2001). Tachakra et al. report that the savings on travel and time within the United Kingdom alone would have paid for the equipment in 1 year for 22 sites. Our discovery that some participants would have preferred to travel to take the course rather than participate in VC may be related to their travel cost being reimbursed. Taking a course F2F gives the students the ability to visit the city for free - a perk that can influence the fair and true assessment of the appropriateness of VC-based education. The influence of such informal perks in decisionmaking (whether to use or not use technology) should be recognized and taken into account when interpreting feedback about innovations.

\section{Recommendations}

The findings of this study support that VC is an appropriate and cost effective way to offer nursing education. Recommendations to improve the VC courses include the enhancement of orientation courses for presenters on videoconference educational techniques, such as methods for improving the use of PowerPoint slides, and increasing the interaction with distant sites. Such orientation would include special instructions for increasing the clarity and presentation of PowerPoint slides to enhance their use in the VC. The importance of continual interaction with distant sites would be encouraged in this orientation session, including increased "flicking" to remote sites to assess for questions or connectivity issues. Clear protocols for technical support should be established including providing support and training to people at remote sites to manage the video-conference linking process (Marrow, Hollyoake et al. 2002; Newman, Martin et al. 2009). Lastly, it is essential that more research needs to be conducted on the effectiveness of VC as a teaching modality, specifically for enhancing much needed specialist nursing skills in under resourced areas. What is the quality of the learning outcomes? Are the skills and methods learned in the VC easily transferrable to the clinical environment? Are the learning objectives retained over time? Are such methods sustainable in under-resourced areas? How adequate is VC for teaching actual clinical skills? These and many other critical questions remain to be answered.

\section{Conclusion}

This initial process evaluation clearly indicates that the two courses have been successfully conducted via VC. The ADM course has resulted in training being provided to 47 registered midwives in rural areas in 2009. This will help to achieve the target of training120 -160 ADMs over 3 years. In addition, a number of Primary Health Care Nurses are being trained in HIV/ARV training annually via the ARV VC, another important contribution to public health in South Africa. In the light of the potential savings of time and money, with specific consideration on how to teach and support the clinical components of these courses, videoconferencing can be used to teach specialist nurses in under-resourced areas. Moreover, considering the healthcare worker human 
resource crises, the use of such techniques as VC should be accelerated. However, much more attention should be given to developing the infrastructure, enhancing teacher skills, specific consideration for clinical skill teaching and supporting further research to make this technology not only available, but commonly used in health services in underresourced public health services and hospitals.

\section{Acknowledgements}

Professor Maurice Mars (Head of School, Department of TeleHealth), Mrs Thandi Ndebele (Course Coordinator ADM course), Ms Fiona Walters, SON and Dr S Pillay and Mr T Nair (Course Director and Course Co-ordinators ECI clinical ARV courses at the University of KwaZulu-Natal).

\section{References}

1 Ahn, H. H., Kim, J. E., Ko, N. Y., Seo, S. H., Kim, S. N. \& Kye, Y. C. (2007). Videoconferencing journal club for dermatology residency training: an attitude study. Acta Dermato Venereologica, 87(5), 397-400.

2 Allen, M., Mann, K., Kells, C., Ferrier, S., O'Connor, N., \& MacDonald, P. (2007). Cardiology grand rounds: effect of videoconferencing on educational value. Journal of Telemedicine and Telecare, 13(3), 136-141.

3 Allen, M., Sargeant, J., \& MacDougall, E. (2002). Videoconferenced continuing medical education in Nova Scotia. Journal of Telemedicine and Telecare, 8(2), 24.

4 Armfield, N. R., Smith, A. C., \& Armfield, N. R. (2007). Education for regional health professionals using mobile videoconferencing. Journal of Telemedicine and Telecare, 13(3), 44-47.

5 Bastos, M. A. R. \& Guimarães, E. M. P. (2003). Distance learning in the nursing area: report of an experience. Revisto Latino-Americano de Enfermagem, 11, 685691.

6 Birden, H. \& Page, S. (2005). Teaching by videoconference: a commentary on best practice for rural education in health professions. Rural Remote Health ,5(2), 356.

7 Bradshaw, D., N. Nannan, et al. (2000). Mortality Estimates for KWA-ZULU NATAL PROVINCE, 2000. South African National Burden of Disease Study, South African Medical Research Council.

8 Bradshaw, D. \& Steyn, K. (2002). Poverty and Chronic Diseases in South Africa: Technical Report 2001, Medical Research Council.

9 Cartwright, J. C. \& Menkens, R. (2002). Student perspectives on transitioning to new technologies for distance learning. Computers Informatics Nursing, 20(4), 143-149.

10 Chang, B. L. \& Trelease, R. (2001). Can telehealth technology be used for the education of health professionals?. Western Journal of Nursing Research, 23(1), 107-114. 
11 Charles, P. A. \& E. M. Mamary (2002). New choices for continuing education: a statewide survey of the practices and preferences of nurse practitioners. Journal of Continuing Education in Nursing, 33(2), 88-91.

12 Chipps, J. A. \& Mars, M. (2009). Technology Enhanced Learning for Remote Nurses in KwaZulu-Natal. IST-Africa 2010 Conference. Durban: http://www.istafrica.org/Conference2010/default.asp?page=paper-repository

13 Cragg, C. E., Andrusyszyn, M. A., \& Humbert, J. (1999). Experience with Technology and Preferences for Distance Education Delivery Methods in a Nurse Practitioner Program. Journal of Distance Education, 14(1), 1-13.

14 Curran, V. R. (2006). Tele-education. Journal of Telemedicine and Telecare, 12(2), 57-63.

15 Curran, V. R., Fleet, L., \& Kirby, F. (2007). A comparative analysis of the perceived continuing medical education needs of a cohort of rural and urban Canadian family physicians. Canadian Journal of Rural Medicine, 12(3), 161-166.

16 Godoy, S., Mendes, I. A. C., Hayashida, M., Nogueira, M. S., \& Alves, L. M. M. (2004). In-service nursing education delivered by videoconference. Journal of Telemedicine and Telecare, 10(5), 303-305.

17 Debourgh, G. A. (2003). Predictors of student satisfaction in distance-delivered graduate nursing courses: what matters most?. Journal of Professional Nursing, 19(3), 149-163.

18 Dillon, E., Loermans, J., Davis, D., \& Xu, C. (2005). Evaluation of the Western Australian Department of Health telehealth project. Journal of Telemedicine and Telecare, 11(2), 19-21.

19 Gobbi, M., Monger, E., Watkinson, G., Spencer, A., Weaver, M., Lathlean, J. \& Bryant S. (2004). Virtual Interactive Practice: a strategy to enhance learning and competence in health care students. In M. et al., Fieschi, (eds), Medinfo, 874-878..

20 Gul, Y. A., Wan, A. C., \& Darzi, A. (1999). Use of telemedicine in undergraduate teaching of surgery. Journal of Telemedicine and Telecare, 5(4), 246-248.

21 Hampton, C. L. (1994). The Interactive Videoconference: An Effective CME Delivery System. Journal of Continuing Education in the Health Professions, 14(2), 83-89.

22 Health Systems Trust. (2009). Health statistics - Health Systems Trust. (2009/11/19) Retrieved 2009/11/19, from http://www.healthlink.org.za/healthstats/11/data.

23 Ho, D., Hu, P., Carmack, D., Hayda, R., Pohl, A., Dunbar, R., Harris, R., \& Frisch, H. (2006). Design and evaluation of International Video Teleconference (iVTC) for orthopedic trauma education. American Medical Informatics Association (AMIA) Annual Symposium Proceedings: 951.

24 Holland, A. J. A., Soundappan, S. V. S., \& Oldmeadow, W. (2008). Videoconferencing surgical tutorials: bridging the gap. ANZ Journal of Surgery, 78(4), 297-301.

25 Jones, R., Skirton, H., \& McMullan, M. (2006). Feasibility of combining e-health for patients with e-learning for students using synchronous technologies. Journal of Advanced Nursing, 56(1), 99-109. 
26 Kerns, A. S., McDonough, J. P., Groom, J. A., Kalynych, N. M., \& Hogan, G. T. Jr. (2006). Televideo conferencing: is it as effective as "in person" lectures for nurse anesthesia education?. American Association of Nurse Anesthetists (AAAN) Journal, 74(1), 19-21.

27 KZN Department of Health. (2009). Advertised Professional Nurse Salaries. Access 24 March 2009 from www.kznhealth.gov.za.

28 Loewen, L., Seshia, M. M. K., Askin, D. F., Cronin, C., \& Roberts, S. (2003). Effective delivery of neonatal stabilization education using videoconferencing in Manitoba. Journal of Telemedicine and Telecare, 9(6), 334-338.

29 MacIntosh, J. (2001). Learner concerns and teaching strategies for videoconferencing. Journal of Continuing Education in Nursing, 32(6), 269-265.

30 Marrow, C. E., Hollyoake, K., Hamer, D., \& Kenrick, C. (2002). Clinical supervision using video-conferencing technology: a reflective account. Journal of Nurse Managers, 10(5), 275-282.

31 Mars, M. (2007). Telemedicine in KwaZulu-Natal: from failure to cautious optimism. Journal of Telemedicine and Telecare, 13(3), 57-59.

32 McInerney, P. A. \& Nkosi, Z. Z. (2007). The use of telecommunications in teaching. Africa Journal of Nursing and Midwifery, 9(2), 5-11.

33 Mekwa, J. (2004). Chapter 13: Transformation in Nursing Education. Retrieved 2009/11/19 from http://www.healthlink.org.za/uploads/files/chapter13 00.pdf.

34 Newman, C., Martin, E., McGarry, D. E., \& Cashin, A. (2009). Survey of a videoconference community of professional development for rural and urban nurses. Rural Remote Health Journal, 9(2), 1134.

35 Norman, R., Bradshaw, D., Schneider, M., Pieterse, D., \& Groenewald, P. (2006). Revised Burden of Disease Estimates for the Comparative Risk Factor Assessment, South Africa 2000. Methodological Note. Cape Town, South African Medical Research Council.

36 Padarath, A., Chamberlain, C., McCoy, D., Ntuli, A., Rowson, M., \& Loewenson, R. (2003). Health personnel in Southern Africa: confronting maldistribution and brain drain. Equinet Discussion Paper 3. R. Loewenson and C. Thompson. Durban, Health Systems Trust.

37 Peres, H. H. \& Leite, M. M. (2008). Innovation and technological interaction at the School of Nursing-USP. Revista da Escola de Enfermagem - USP, 42(4), 614619.

38 Pistorius, C. W. I. \& Du Pisani, L. A. (1997). Beyond the borders of South Africa distance education via satellite television: a report on the status and potential of Interactive Teaching ITT at the University of Pretoria. SAOUG Archive Fourth South Africa Online Volume: www.saoug.org.za/archive/1997/9708.pdf

39 Post, P. A., Carusetta, E., Maher, E., \& Macintosh, J. (1998). Not the Wand But the Wizard. Canadian Journal of University Continuing Education, 24, 21-36.

40 Regnard, C. (2000). Using videoconferencing in palliative care. Palliative Medicine, 14(6), 519-28. 
41 Sawada, I., Sugiyama, A., Ishikawa, A., Ohyanagi, T., Saeki, K., Izumi, H., Kawase, S., \& Matsukura, K. (2000). Upgrading rural Japanese nurses' respiratory rehabilitation skills through videoconferencing. Journal of Telemedicine and Telecare, 6(2), 69-71.

42 Seibert, D. C., Guthrie, J. T., \& Adamo, G. (2004). Improving learning outcomes: integration of standardized patients \& telemedicine technology. Nursing Education Perspectives, 25(5), 232-237.

43 Seixas, C.A., Mendes, I. A. C., Godoy, S., \& Costa, A. L. (2004). Implantation of a videoconferencing system applied to nursing research and teaching environments. Revista Brasileira de Enfermagem, 57(5), 620-624.

44 Stain, S., Mitchell, M., Belue, R., Mosley, V., Wherry, S., Adams, C.Z., Lomis, K., \& Williams, P. C. (2005). Objective assessment of videoconferenced lectures in a surgical clerkship. American Journal of Surgery, 189(1), 81-84.

45 Tachakra, S. \& Creagh-Brown, B. (2001). Using telemedicine for distance education. Journal of Telemedicine and Telecare, 7(1), 43-44.

46 van Boxel P., Anderson, K., \& Regnard, C. (2003). The effectiveness of palliative care education delivered by videoconferencing compared with face-to-face delivery. Palliative Medicine, 17(4), 344-358.

47 Weber, J. R. \& Lawlor, A. C. (1998). Professional nursing series by videoconferencing. J Contin Educ Nurs, 29(4), 161-164.

48 WHO (2006). World Health Report 2006 - Working Together for Health. Retrieved 2009, from http://www.who.int/whr/2006/en/.

49 Winters, J. M. (2007). Videoconferencing and telehealth technologies can provide a reliable approach to remote assessment and teaching without compromising quality. Journal of Cardiovascular Nursing, 22(1), 51-57.

50 Zerr, D. M. \& Pulcher, K. L. (2008). Using interactive video technology in nursing education: a pilot study. Journal of Nursing Education, 47(2), 87-91. 